\title{
Diethyldithiocarbamate inhibits iNOS expression in human lens epithelial cells stimulated by IFN-gamma and LPS
}

\author{
De-xin LI, Si-ling WANG ${ }^{1}$, Yoshimasa ITO ${ }^{2,3}$, Jing-hai ZHANG, Chun-fu WU \\ Department of Pharmaceutics, College of Pharmacy, Shenyang Pharmaceutical University, Shenyang 110016, China; ${ }^{2}$ School of Pharmacy, ${ }^{3}$ Pharma- \\ ceutical Research and Technology Institute, Kinki University, Osaka 577-8502, Japan
}

\section{Key words}

human lens; epithelial cells; inducible nitric oxide synthase; interferon gamma; lipopolysaccharide; diethyldithiocarbamate

\author{
${ }^{1}$ Correspondence to Prof Si-ling WANG. \\ Phn 86-24-2384-3711, ext 3641. \\ E-mail silingwang@hotmail.com \\ Received 2004-05-06 \\ Accepted 2004-10-29 \\ doi: 10.1111/j.1745-7254.2005.00041.x
}

\begin{abstract}
Aim: To investigate the biological activity of human lens epithelial cells (HLEC) in producing inducible nitric oxide synthase (iNOS) and nitric oxide (NO), and to assesse the effect of diethyldithiocarbamate (DDC) on iNOS mRNA levels and expression of NOS. Methods: The human lens epithelial cell line SRA 01/04 was used in this experiment. Semi-quantitative reverse transcription polymerase chain reaction (RT-PCR) and Western blotting were used to detect, respectively, iNOS mRNA expression and protein production. Results: A costimulation by interferon gamma (IFN- $\gamma$ ) and lipopolysaccharide (LPS) was necessary for iNOS expression in HLEC. The expression of iNOS was significantly reduced in a dosedependent manner by adding DDC from $10 \mu \mathrm{mol} / \mathrm{L}$ to $1 \mathrm{mmol} / \mathrm{L}$. Conclusion: The expression of iNOS in HLEC needs co-stimulation with IFN- $\gamma$ and LPS and it is inhibited by DDC.
\end{abstract}

\section{Introduction}

Cataracts are still the most important cause of blindness in the world and are a significant and increasing global problem. The mechanism of cataract development is complicated and involves many factors. For many years, we have been involved in the development of anti-cataract treatments and investigating the mechanisms of cataract development. Our previous studies on selenite-induced rat cataracts demonstrated that the NO concentration in ocular tissue was significantly higher than in normal rats. Inducible nitric oxide synthase (iNOS or NOS2) is thought to play a role in the initiation of cataracts, and the development of cataracts is prevented by NOS inhibitors ${ }^{[1]}$. We researched whether NO was produced by the ocular tissues or comes from other parts of the body, so we selected human lens epithelial cells (HLEC) for further study.

Inducible NOS, one of the three isoforms of NOS, catalyses the oxidization of $L$-arginine and generates large amounts of $\mathrm{NO}^{[2]}$; it does not require elevated intracellular $\mathrm{Ca}^{2+}$ levels for activation. In addition, its function lasts for a longer period than that of constitutive NOSs (endothelial NOS, eNOS; neural NOS, nNOS). Inducible NOS can be produced by treatment with agents, such as cytokines, interferons and bacterial lipopolysaccharide (LPS), in a wide variety of cell types such as macrophages, hepatocytes, keratinocytes, endothelial cells, and epithelial cells ${ }^{[3-7]}$. In the eye, eNOS and nNOS are localized in the retina, ciliary body and conjunctiva, and are thought to be involved in neurotransmission, regulation of intraocular pressure and vasodilation, while iNOS is involved in endotoxin-induced uveitis and inflammation of the anterior segment of the eye, and inhibits the cellular proliferation of retinal pigment epithelial cells ${ }^{[8,9]}$. Therefore, the purpose of this study is to investigate the biological activity of HLEC in iNOS expression and NO production.

Diethyldithiocarbamate (DDC), a potent free radical scavenger, has been found to prevent selenite-induced opacity in cultured rat lenses ${ }^{[10]}$. This was thought to be related to its anti-oxidant effect. It has been reported that both $\mathrm{NO}$ and its derivative peroxynitrite $\left(\mathrm{ONOO}^{-}\right)$inhibit mitochondrial respiration and may increase oxygen radical production by mitochondria. Large or persistent levels of NO promote mitochondrial oxidant formation, and inhibit the respiratory chain complexes, probably by nitrosylating or oxidizing protein thiols and removing iron from the iron-sulphur centres. 
Peroxynitrite causes irreversible inhibition of mitochondrial respiration and damage to a variety of mitochondrial components via oxidizing reactions, most notably at complexes I and II of the electron transport chain, ATPase, aconitases, and Mn-superoxide dismutase ${ }^{[11,12]}$. These damages lead to deficient energy metabolism. Usually, in the initiation of cataractogenesis, deficient energy metabolism occurs with mitochondria function disorder. Thus, the effect of DDC for the prevention of NO overproduction was also investigated in this study.

\section{Materials and methods}

Materials DDC and bovine serum albumin (BSA) were purchased from Wako Pure Chemical Industries Ltd (Osaka, Japan). Dulbecco's modified Eagle's medium (low glucose) (DMEM), fetal bovine serum (FBS), 0.05\% trypsin-EDTA solution and phosphate buffered saline (PBS) were purchased from GIBCO $^{\mathrm{TM}}$ Invitrogen Co (Tokyo, Japan). Gentamicin reagent solution $(10 \mathrm{~g} / \mathrm{L})$ was obtained from GIBCO BRL Life Technologies (Japan). Interferon- $\gamma($ IFN- $\gamma$ ) was purchased from PeproTech EC Ltd (London, UK). LPS purified from Escherichia coli was obtained from Sigma-Aldrich Co (St Louis, MO, USA). Protease inhibitor cocktail tablets were obtained from Complete Roche Applied Science (Japan). All the primers used were synthesized by Sigma Genosys (Sigma Genosys, Japan, KK). Alkaline phosphatase (AP)-conjugated anti-rabbit IgG and ProtoBlot II AP System with Stabilized Substrate (BCIP/NBT) were obtained from Promega Co. All other chemicals used, except where indicated, were of analytical grade.

Cell culture and treatments The human lens epithelial cell line SRA 01/04 was provided by Ibaraki Medical University, and maintained in DMEM supplemented with $10 \%(\mathrm{v} / \mathrm{v})$ heat-inactivated FBS and $10 \mathrm{mg} / \mathrm{L}$ gentamicin at $37{ }^{\circ} \mathrm{C}$ in a humidified $\mathrm{CO}_{2}$ incubator (ESPEC BNA-111, TABAI ESPEC CORP, Japan) with $5 \% \mathrm{CO}_{2}$. Culture medium was changed every other day. The confluent cells were separated and trypsinized with $0.05 \%$ trypsin-EDTA to produce single cells, after which they were seeded at $4 \times 10^{4} \mathrm{~cm}^{-2}$ and allowed to form subcultures. Cell viability was assessed by Trypan blue exclusion assay. Each treatment was carried out on $\mathrm{d} 3$ after seeding, when the cells were $80 \%$ confluent. The culture medium was changed every other day for routine culture, and then $1 \mathrm{~h}$ before each experiment. All cultures were carried out in duplicate.

Semiquantitative reverse transcription-polymerase chain reaction (RT-PCR) for iNOS mRNA evaluation Total cellular RNA was extracted and purified from HLEC with the RNeasy Mini Kit and RNase-Free DNase Set (QIAGEN KK, Tokyo, Japan) according to the manufacturer's instructions. The RNA level was quantified by measuring the absorbance at $260 \mathrm{~nm}$. The samples with a ratio of 260/280 nm greater than 1.8 were used. RT-PCR was performed using the RNA PCR Kit (AWV Ver 2.1, TAKARA BIO INC, Tokyo, Japan). As a control for calibrating an equivalent amount of input cDNA, the mRNA level of constitutively expressed G3PDH was determined in parallel aliquots of cDNA to control any differences in cDNA synthesis efficiency. In general, total RNA $1 \mu \mathrm{g}$ was added to a $20 \mu \mathrm{L}$ volume of reaction medium for reverse transcription, and all PCR procedures were performed using a volume of $50 \mu \mathrm{L}$ according to the manufacturer's instructions. The primers used in this study were as follows: iNOS (sense, 5'CCAGT GACAC AGGAT GACCT TCAG-3' and antisense, 5'-TGCCA TTGTT GGTGG AGTAA CG-3'), and human G3PDH (sense, 5'-CATCA CCATC TTCCA GGAGC GAGA-3' and antisense, 5'-CCACC ACCCT GTTGC TGTAG CCA-3'). The cycling conditions were: 35 cycles for iNOS and 20 cycles for G3PDH at $94{ }^{\circ} \mathrm{C}$ for $30 \mathrm{~s}, 65^{\circ} \mathrm{C}$ for $30 \mathrm{~s}$, and $72{ }^{\circ} \mathrm{C}$ for $1 \mathrm{~min}$ for amplifying $603 \mathrm{bp}$ and 752 bp products, respectively. Finally, the extension of products was performed at $72{ }^{\circ} \mathrm{C}$ for $10 \mathrm{~min}$. PCR-amplified samples were run on $1.5 \%$ agarose gel and visualized using ethidium bromide, and then photographed (ImageMaster VDS-CL, Amersham Biosciences) under UV light.

Western blotting for determination of iNOS protein At the end of the treatment, cells were washed with ice-cold phosphate buffer and removed from plates by a cell scraper and centrifuged at $200 \times \mathrm{g}$ for $5 \mathrm{~min}$. The cell pellets were then suspended in $200 \mu \mathrm{L}$ lysis buffer (Tris $\cdot \mathrm{HCl} 50 \mathrm{mmol} / \mathrm{L}$, $\mathrm{pH}$ 7.6, protease inhibitor cocktail tablet in PBS $150 \mathrm{mmol} / \mathrm{L}$, Triton X-100 0.5\%) and lysed for $30 \mathrm{~min}$ on ice. The cell debris was removed by centrifugation at $12000 \times g$ at $4{ }^{\circ} \mathrm{C}$ for $20 \mathrm{~min}$. The protein concentration was determined using a protein assay kit (Bio-Rad Laboratories, CA, USA) with BSA as the standard. A sample of total protein $(20 \mu \mathrm{g})$ was separated on an $8 \%$ polyacrylamide sodium dodecyl sulfate (SDS) gel. The proteins were then transferred to polyvinylidene difluoride (PVDF) membranes (BIO-RAD, CA, USA), using a semi-dry transfer cell (TRans-Blot SD Semi-Dry Electrophoretic Transfer Cell, BIO-RAD, CA, USA). The transfer buffer used in the system contained Tris $\cdot \mathrm{HCl} 25 \mathrm{mmol} / \mathrm{L}$, glycine $192 \mathrm{mmol} / \mathrm{L}$, methanol 20\%, and SDS 0.0375\%. After transfer, nonspecific sites on the membranes were blocked with $5 \%$ non-fat dry milk in PBS. The blots were probed with $1 \mathrm{mg} / \mathrm{L}$ rabbit anti-human iNOS polyclonal antibody (Santa Cruz Biotechnology Inc, CA, USA) overnight at 
$4{ }^{\circ} \mathrm{C}$ followed by washing several times with PBS- $0.1 \%$ Tween 20 (PBST). A secondary alkaline-phosphatase conjugated anti-rabbit IgG (1:7500 dilutions) was added, and incubated for $1 \mathrm{~h}$ at room temperature. After washing several times in PBST, iNOS proteins were visualized by BCIP/NBT kit.

\section{Results}

Induction of iNOS mRNA The expression of iNOS has been studied in most detail in murine macrophages where maximum expression can be induced by a combination of IFN- $\gamma$ and $\operatorname{LPS}^{[16]}$. Figure 1 showed that non-stimulated HLEC had undetectable levels of iNOS mRNA (lane 1). Stimulation with LPS or IFN- $\gamma$ alone for $3 \mathrm{~h}$ had a negligible effect on iNOS mRNA induction (lanes 2 and 3). HLEC, pretreated with IFN- $\gamma$ for $3 \mathrm{~h}$, then washed twice with PBS, followed by an incubation with LPS for $3 \mathrm{~h}$, had a very thin band (lane 4), whereas, cells treated with IFN- $\gamma$ for $3 \mathrm{~h}$ followed by co-incubation with LPS and IFN- $\gamma$, produced a substantial amount of iNOS mRNA (lane 5).

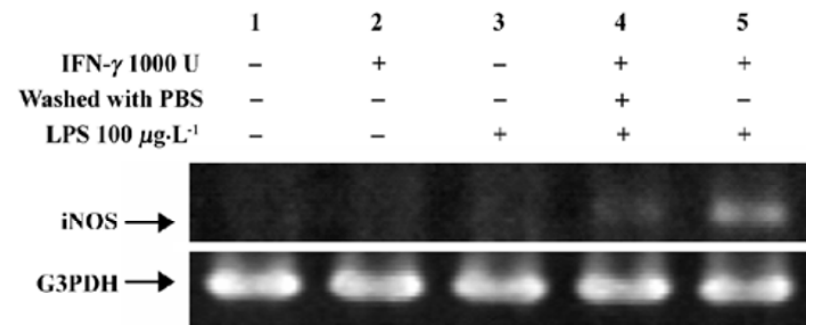

Figure 1. Transcription of iNOS mRNA in HLEC treated with/without IFN- $\gamma$ and LPS. Representative results of the 3 independent experiments are shown.

Increasing the amount of LPS from $1 \mu \mathrm{g} / \mathrm{L}$ to $1 \mathrm{mg} / \mathrm{L}$ resulted in a corresponding increase of iNOS mRNA levels (Figure 2A). With the co-incubation time increase, the intensity of the iNOS bands tended to increase (Figure 2B). On the contrary, extending the pretreatment time of IFN- $\gamma$ from $1 \mathrm{~d}$ to $2 \mathrm{~d}$ did not produce a stronger iNOS band (Figure 2C, lane 5 vs 3).

Inhibitory effect of DDC on iNOS expression Figure 3 shows the effect of DDC on iNOS mRNA expression. Incubation with LPS, IFN- $\gamma$, or DDC alone failed to produce iNOS mRNA or protein, while the combination of LPS and IFN- $\gamma$ resulted in the expression of iNOS (lane 4), and the expression was inhibited by adding DDC to the culture medium (lane 5). However, the induction of iNOS by LPS and

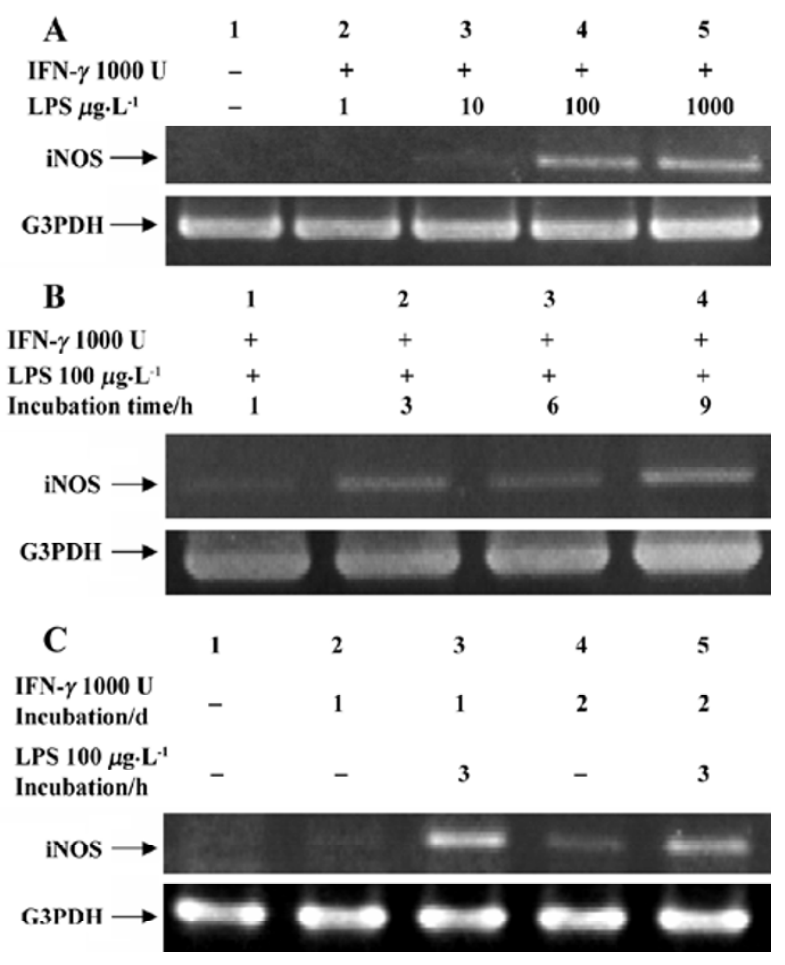

Figure 2. Transcription of iNOS mRNA in HLEC. HLEC were pretreated with IFN- $\gamma$ for $3 \mathrm{~h}$ followed by co-incubation (A) with LPS at different concentrations, (B) with LPS for indicated time intervals, and (C) pretreated with IFN- $\gamma$ for 1 day or 2 day followed by a coincubation with/without LPS for another $3 \mathrm{~h}$. Representative results of the 3 independent experiments are shown.

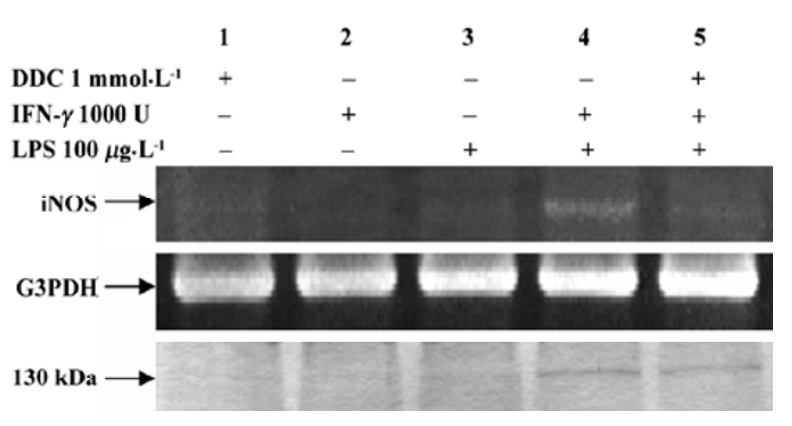

Figure 3. Inhibitory effect of DDC on iNOS mRNA transcription and protein production. HLEC were pretreated with/without IFN- $\gamma$ in the presence/absence of DDC for $3 \mathrm{~h}$, followed by a $24-\mathrm{h}$ coincubation with/ without LPS. Representative results of the 3 independent experiments are shown.

IFN- $\gamma$ was attenuated in HLEC that had been loaded with DDC. In addition, the inhibitory effect was enhanced at increased DDC concentrations from $10 \mu \mathrm{mol} / \mathrm{L}$ to $1 \mathrm{mmol} / \mathrm{L}$ (Figure 4). 


\begin{tabular}{|c|c|c|c|c|c|c|}
\hline & 1 & 2 & 3 & 4 & 5 & 6 \\
\hline DDC $1 \mathrm{mmol} \cdot \mathrm{L}^{-1}$ & - & + & - & 1000 & 100 & 10 \\
\hline IFN- $\gamma 1000 \mathrm{U}$ & - & - & + & + & + & + \\
\hline LPS $100 \mu \mathrm{g} \cdot \mathrm{L}^{-1}$ & - & - & + & + & + & + \\
\hline $\mathrm{iNOS} \longrightarrow$ & & & -0 & 6 & $x^{2}+2$ & 70 \\
\hline
\end{tabular}

Figure 4. Relationship between DDC concentrations and inhibitory effect on iNOS mRNA transcription. HLEC were treated with/without IFN$\gamma$ in the presence/absence of DDC for $3 \mathrm{~h}$, followed by a 24-h coincubation with/without LPS. Representative results of the 3 independent experiments are shown.

\section{Discussion}

The present research reports the expression of iNOS mRNA in HLEC stimulated with LPS and IFN- $\gamma$. The coincubation of both factors is needed for a quick cellular response and large amount of iNOS mRNA production, compared with stimulation with LPS or IFN- $\gamma$ alone or successively. The synergistic effect between LPS and IFN- $\gamma$, as far as the transcription of iNOS mRNA is concerned, has been extensively investigated in mouse macrophages ${ }^{[15-17]}$. LPS is a common initiator of inflammation, triggering tyrosine phosphorylation and activation of mitogen-activated protein kinases (MAPKs) ${ }^{[18]}$. MAPKs phosphorylate and regulate a variety of transcription factors, leading to inflammatory gene expression $^{[19]}$. In several cell types, LPS also activates transcription nuclear factor kappa B (NF- $\mathrm{kB}$ ) and regulates iNOS gene expression ${ }^{[20]}$. The synthesis of iNOS is mainly regulated at the transcriptional level. The promoter region of the iNOS gene from different species has been reported to contain binding sites for several transcription factors. Those known to be active include $\mathrm{\kappa B}$ sites located both in the enhancer and basal promoter ${ }^{[20,21]}$, two juxtaposed enhancerlinked IFN-stimulated response elements (ISREs), the distal one of which is a strong activator ${ }^{[2,21]}$, while the proximal one is a weak activator of transcription ${ }^{[22]}$, and an octamer element in the basal promoter ${ }^{[21]}$. An IFN- $\gamma$ activated site (GAS) is necessary for full expression of the mouse iNOS gene in response to IFN- $\gamma$ and LPS. The binding of Stat $1 \alpha$ to the GAS of the iNOS promoter is required for optimal induction of the iNOS gene by IFN- $\gamma$ and $\mathrm{LPS}^{[23]}$. Also, iNOS gene expression appears to require the simultaneous presence of all transcription factors binding to their enhancers. When all are present, transcription is enhanced; when any one of them is absent, the transcription level is reduced or completely stopped. In the case of humans, transcriptional regulation is a crucial factor in the initiation of cytokine- stimulated NO production by human iNOS ${ }^{[24]}$. The two activator protein-1 sites, as well as the upstream NF- $\mathrm{kB}$ site, are important for LPS and IFN- $\gamma$ stimulation of human iNOS induction.

Activation of NF- $\kappa B$ seems to be an essential step for iNOS induction in most cell types, and the inhibitory effect of DDC on the transcriptional activity of the iNOS gene may be due to an effect on the activation of transcription factor $\mathrm{NF}-\mathrm{\kappa B}$, which regulates the expression of a variety of genes essential for cellular immune response, inflammation, growth, and development. Because dithiocarbamates are well-known antioxidants and NF- $\mathrm{KB}$ inhibitors ${ }^{[25,26]}$, and DDC, a dithiocarbamate analogue, exhibits concentration-dependent biphasic effects in inhibiting NF- $\mathrm{KB}$ activation in cerebral endothelial cells ${ }^{[27]}$, that is, it inhibits NF- $\mathrm{KB}$ activation at low but not high concentrations $(>500 \mu \mathrm{mol} / \mathrm{L})$. The present studies investigated the inhibitory effect of DDC at concentrations ranging from $10 \mu \mathrm{mol} / \mathrm{L}$ to $1 \mathrm{mmol} / \mathrm{L}$, and no biphasic effect was observed. If a biphasic effect does exist in HLEC, the "high concentration" should be more than $1 \mathrm{mmol} / \mathrm{L}$. Our previous studies on the ocular bioavailability of disulfiram (DSF), which is a dimer of DDC and quickly converted into DDC by catalysis of the protein mercapto group in the cornea and aqueous humor, demonstrated that the concentration of DDC in the aqueous humor was not more than 100 $\mu \mathrm{mol} / \mathrm{L}$ after topical administration. Thus, if DSF is used as an anticataract agent for the prevention and treatment of cataracts, the main problem we need to consider is how to enhance the corneal permeability and bioavailability of DSF preparations. Whether the anticataract effect of DDC is due to its inhibition of NF- $\mathrm{KB}$ or not, the signal transduction pathway linking stimulation of iNOS mRNA in HLEC needs to be clarified by further investigations.

In conclusion, the present study reports the expression of iNOS in HLEC, which shows that co-stimulation of IFN- $\gamma$ and LPS is required, while the expression is inhibited by DDC.

\section{Acknowledgment}

We are most grateful to Dr David JACK for comments and suggestions on our manuscript.

\section{References}

1 Ito Y, Nabekura T, Takeda M, Nakao M, Terao M, Hori R, et al. Nitric oxide participates in cataract development in selenite-treated rats. Curr Eye Res 2001; 22: 215-20.

2 Moncada S, Higgs A. The $L$-arginine-nitric oxide pathway. N Engl J Med 1993; 329: 2002-12.

3 Griffth OW, Stuehr DJ. Nitric oxide synthases: properties and cata- 
lytic mechanism. Annu Rev Physiol 1995; 57: 707-36.

4 Asano K, Chee CB, Gaston B, Lilly CM, Gerard C, Drazen JM, et al. Constitutive and inducible nitric oxide synthase gene expression, regulation, and activity in human lung epithelial cells. Proc Natl Acad Sci USA 1994; 91: 10089-93.

5 Fimiani C, Magazine H, Welters ID, Bilfinger TV, Salsano F, Tonnesen $\mathrm{E}$, et al. Antagonism of LPS and IFN-gamma induced iNOS expression in human atrial endothelia by morphine, anandamide, and estrogen. Acta Pharmacol Sin 2000; 21: 405-9.

6 Salzman AL, Eaves-Pyles T, Linn SC, Denenberg AG, Szabo C. Bacterial induction of inducible nitric oxide synthase in cultured human intestinal epithelial cells. Gastroenterology 1998; 114: 93-102.

7 Hussaini IM, Zhang YH, Lysiak JJ, Shen TY. Dithiolane analogs of lignans inhibit interferon-gamma and lipopolysaccharide-induced nitric oxide production in macrophages. Acta Pharmacol Sin 2000; 21: 897-904.

8 Jacquemin E, de Kozak Y, Thillaye B, Courtois Y, Goureau O. Expression of inducible nitric oxide synthase in the eye from endotoxininduced uveitis rats. Invest Ophthalmol Vis Sci 1996; 37: 1187-96.

9 Goureau O, Lepoivre M, Becquet F, Courtois Y. Differential regulation of inducible nitric oxide synthase by fibroblast growth factors and transforming growth factor $\gamma$ in bovine retinal pig mented epithelial cells: inverse correlation with cellular proliferation. Proc Natl Acad Sci USA 1993; 90: 4276-80.

10 Ito Y, Cai H, Terao M, Tomohiro M. Preventive effect of diethyldithiocarbamate on selenite-induced opacity in cultured rat lenses. Ophthalmic Res 2001; 33: 52-9.

11 Brown GC. Nitric oxide and mitochondrial respiration. Biochim Biophys Acta 1999; 1411: 351-69.

12 Radi R, Cassina A, Hodara R. Nitric oxide and peroxynitrite interactions with mitochondria. Biol Chem 2002; 383: 401-9.

13 Moncada S, Palmer RM, Higgs EA. Nitric oxide: physiology, pathophysiology, and pharmacology. Pharmacol Rev 1991; 43: 10942 .

14 Lorsbach RB, Murphy WJ, Lowenstein CJ, Snyder SH, Russell SW. Expression of the nitric oxide synthase gene in mouse macrophages activated for tumor cell killing. Molecular basis for the synergy between interferon-gamma and lipopolysaccharide. J Biol Chem 1993; 268: 1908-13.

15 Xie QW, Whisnant R, Nathan C. Promoter of the mouse gene encoding calcium-independent nitric oxide synthase confers inducibility by interferon gamma and bacterial lipopolysaccharide. J Exp Med 1993; 177: $1779-84$.

16 Lowenstein CJ, Alley EW, Raval P, Snowman AM, Snyder SH, Russell $\mathrm{SW}$, et al. Macrophage nitric oxide synthase gene: two upstream regions mediate induction by interferon gamma and lipopolysaccharide. Proc Natl Acad Sci USA 1993; 90: 9730-4.

17 Gao J, Morrison DC, Parmely TJ, Russell SW, Murphy WJ. An interferon- $\gamma$-activated site (GAS) is necessary for full expression of the mouse iNOS gene in response to interferon- $\gamma$ and lipopolysaccharide. J Biol Chem 1997; 272: 1226-30.

18 Weinstein SL, Sanghera JS, Lemke K, DeFranco AL, Pelech SL. Bacterial lipopolysaccharide induces tyrosine phosphorylation and activation of mitogen-activated protein kinases in macrophages. J Biol Chem 1992; 267: 14955-62.

19 Neary JT. MAPK cascades in cell growth and death. News Physiol Sci 1997; 12: 286-93.

20 Xie Q, Kashiwabara Y, Nathan C. Role of transcription factor NF$\kappa \mathrm{B} / \mathrm{Rel}$ in induction of nitric oxide synthase. J Biol Chem 1994; 269 : 4705-8.

21 Goldring CE, Reveneau S, Algarte M, Jeannin JF. In vivo footprinting of the mouse inducible nitric oxide synthase gene: inducible protein occupation of numerous sites including Oct and NF-IL6. Nucleic Acids Res 1996; 24: 1682-7.

22 Kamijo R, Harada H, Matsuyama T, Bosland M, Gerecitano J, Shapiro $\mathrm{D}$, et al. Requirement for transcription factor IRF-1 in NO synthase induction in macrophages. Science 1994; 263: 1612-5.

23 Martin E, Nathan C, Xie QW. Role of interferon regulatory factor 1 in induction of nitric oxide synthase. J Exp Med 1994; 180: 977-84.

24 de Vera ME, Shapiro RA, Nussler AK, Mudgett JS, Simmons RL, Morris SMJ, et al. Transcriptional regulation of human inducible nitric oxide synthase (NOS2) gene by cytokines: initial analysis of the human NOS2 promoter. Proc Natl Acad Sci USA 1996; 93: 1054-9.

25 Moellering D, McAndrew J, Jo H, Darley-Usmar VM. Effects of pyrrolidine dithiocarbamate on endothelial cells: protection against oxidative stress. Free Radic Biol Med 1999; 26: 1138-45.

26 Schreck R, Meier B, Mannel DN, Droge W, Baeuerle PA. Dithiocarbamates as potent inhibitor of nuclear factor $\mathrm{kB}$ activation in intact cells. J Exp Med 1992; 175: 1181-94.

27 Kim CH, Kim JH, Moon SJ, Hsu CY, Seo JT, Ahn YS. Biphasic effect of dithiocarbamates on the activity of nuclear factor- $\kappa \mathrm{B}$. Eur $\mathrm{J}$ Pharmacol 2000; 392: 133-6. 